in vivo $34: 1-9(2020)$

doi:10.21873/invivo.11739

Review

\title{
Reasons to Reconsider Risk Associated With Power Morcellation of Uterine Fibroids
}

\author{
CARSTEN HOLZMANN ${ }^{1}$, WOLFGANG KUEPKER ${ }^{2}$, BIRGIT ROMMEL ${ }^{3}$, \\ BURKHARD HELMKE ${ }^{4 *}$ and JOERN BULLERDIEK ${ }^{1,3^{*}}$ \\ ${ }^{1}$ Institute of Medical Genetics, University Rostock Medical Center, Rostock, Germany; \\ ${ }^{2}$ Center for Minimal Invasive Gynecology, Endometriosis and Reproductive Medicine, Baden Baden-Buehl, Germany; \\ ${ }^{3}$ Human Genetics, University of Bremen, Bremen, Germany; \\ ${ }^{4}$ Institute of Pathology, Elbe Clinics, Stade Clinic, Stade, Germany
}

\begin{abstract}
Our insights into the molecular pathogenesis of uterine smooth muscle tumors have improved significantly. Accordingly, in the present review, we advocate a more refined risk assessment for patients considering surgical removal of fibroids or hysterectomy, respectively, requiring morcellation. For this procedure, the risk estimates given for the iatrogenic spread of a previously unexpected malignancy considerably vary among different studies. Nearly all previous studies conducted retrospectively refer to the risk of a patient having an unexpected malignancy at the time of surgery. We feel that, more appropriately, risk should refer to the number of tumors because, as a rule, every single nodule arises independently and, thus, carries an independent risk of being malignant or not. Furthermore, whether so-called parasitic fibroids carry an underestimated risk of stepwise malignant transformation is discussed.
\end{abstract}

The risk of spreading a malignancy which is associated with power morcellation during laparoscopic hysterectomy or myomectomy is a matter of an ongoing medical, scientific, and even legal discussion. A thorough review addressing different issues of power morcellation and its risks was published recently in this journal (1). The present review addresses an

This article is freely accessible online.

*These Authors contributed equally to this study.

Correspondence to: Joern Bullerdiek, Human Genetics, University of Bremen, D-28359 Bremen, Germany. E-mail: bullerd@unibremen.de

Key Words: Uterine smooth muscle tumors, power morcellation, risk assessment, number of fibroids, parasitic leiomyomas, review. aspect that was not covered in that review, namely implications related to the genetic basis of fibroid development. We feel that this point should be taken into account when considering the pros and cons of procedures requiring power morcellation and thus warrants an additional review.

As a main part of the discussion on the risks of power morcellation, increased mortality following open procedures compared to laparoscopic approaches requiring morcellation is weighed against a lower risk of iatrogenic spread of an unexpected malignancy such as in leiomyosarcoma (LMS). Base-case estimates for procedure-related deaths led Siedhoff and co-workers to the conclusion that at a hypothetical LMS incidence of 0.0015 , mortality for both groups, i.e. laparoscopic versus abdominal hysterectomy, is equivalent (2). This appears to be close to but higher than the incidence of LMS among women undergoing hysterectomy due to presumed fibroids which the same authors estimate to be around 0.0013 . According to these minor differences that have been observed between the two different types of risk, laparoscopic hysterectomy was calculated to result in slightly more quality-adjusted life years than abdominal hysterectomy (499,171 vs. 490,711 over 5 years). This prompted us briefly to review the tumor genetics point of view because we feel that in the past three topics which are covered in this review have received only little or no attention at all but should encourage re-reconsideration of risk figures and further studies. Before going into the details of these three topics, we briefly review the genetic alterations found in benign, borderline, and malignant smooth muscle tumors of the uterus.

\section{The Genetic Background of Uterine Fibroid Development}

Molecular studies have revealed that, like other benign and malignant tumors, fibroids, in the majority of cases, are of 
monoclonal origin with nearly every individual nodule having its own independent history and pathogenesis. This independent monoclonal origin of the single fibroids of individual patients was pointed out already in early studies based on the inactivation patterns of the two alleles of genes mapping to the $\mathrm{X}$ chromosome and later confirmed by a variety of independent studies (3-6). In contrast to multiple uterine fibroids, multiple lesions found in benign metastasizing leiomyoma disease apparently often share the same genetic alterations, indicating their origin from a monoclonal lesion, presumably a single benign uterine fibroid $(7,8)$. More recently, impressive studies on the heterogeneity of driver mutations among multiple fibroids of the same patient have been presented, the results of which confirm the independent origin of nearly every single lesion (9-12).

Alterations of the genes encoding the two DNA-binding proteins mediator complex subunit 12 (MED12) and highmobility group protein AT-hook 2 (HMGA2) seem to drive tumorigenesis mutually exclusively in single tumors (13-15) and constitute the two most frequent types of driver mutations in fibroids $(9,10,14,15)$ with those of MED12 being highly predominant in women with multiple fibroids $(13,16,17)$. Accordingly, both types of mutations characterize independent tumor entities that can also be distinguished based on certain clinical and histological parameters $e . g$. their size and stromal content $(18,19)$, their gene-expression patterns (20), and metabolome (21), and may even differ with respect to their cellular growth capacity in vitro (22). Moreover, they even very rarely coexist among the individual tumors of single patients (23). Interestingly, both main genetic alterations seen in subsets of uterine fibroids are also found in separate subgroups of fibroadenomas of the breast (24-26) and, akin to the situation in smooth muscle tumors of uncertain malignant potential (STUMP) and uterine leiomyosarcomas, MED12 mutations are also a frequent finding in benign as well as in malignant phyllodes tumors (27-29).

Besides these two frequent genetic subgroups, other less frequent genetic alterations are found in double-negative (lacking MED12 mutations as well as HMGA2 rearrangements) fibroids $(30,31)$ that also present with a higher percentage of histological variants. Nevertheless, it has been demonstrated that in these cases as well, single fibroids usually can be distinguished based on the individual mutations they carry (9). Some of these latter genetic alterations, e.g. full or partial monosomy of chromosome 22, may endow tumors with a higher risk of malignant transformation $(32,33)$.

\section{Malignant Transformation of Uterine Fibroids - Fact or Fiction?}

The question as to whether uterine fibroids may (rarely) undergo malignant transformation has been a matter of debate for many years. Recently, the results of genetic analyses have offered additional evidence for such a transformation. Regarding uterine leiomyosarcomas and STUMP, a subset of these shares genetic alterations occurring in fibroids, in particular mutations of MED12 (34-41). This suggests an albeit very low probability of malignant transformation within pre-existing fibroids, in particular with cellular or symplastic areas (42) leading to STUMP and leiomyosarcomas. This is in accordance with previous studies demonstrating the presence of morphologically benign tumoral areas in a considerably high percentage of leiomyosarcomas $(42,43)$, as well as common genetic alterations as outlined above and summarized by Mittal et al. (42). In addition, patients apparently experiencing malignant transformation of leiomyomas, atypical leiomyomas, benign metastasizing leiomyomas or STUMP to leiomyosarcomas $(33,44-47)$ have been described repeatedly. In contrast, evidence for the existence of a considerable percentage of STUMP or leiomyosarcomas with $H M G A 2$ rearrangement is lacking.

In summary, genetic studies on benign, borderline, and malignant smooth muscle tumors of uterine origin suggest a very low but existent probability of malignant transformation of initially benign tumors. A genetic classification of these lesions may be not only of diagnostic but also of predictive relevance (48-52) and should be mandatory for future clinical studies.

\section{The Number of Tumors as a Potential Independent Risk Factor}

Lessons from tumor genetics in general make it highly reasonable to assume that due to their independent molecular origin, every nodule carries its own and independent risk of being malignant. Vice versa, it is tempting to assume that with an increasing number of nodules, a linear increase of the risk of morcellating a malignant tumor is likely to be expected. Accordingly, for future studies the number of fibroids examined should be given in addition to the mere number of patients.

Actually, the number of tumors can be expected to act as an independent risk modifier. For example, if a study with adequate sampling has revealed a risk of having de novo LMS at the time of surgery of about 1/1,000 patients and if in the study population, the average number of tumors is three, a patient with just one tumor has a risk of malignancy of $1 / 3,000$, whereas a patient with three nodules has a risk of 3/3,000 and a patient with six tumors of 6/3,000.

Because we have to consider not only de novo LMS but also eutopic malignant transformation of uterine leiomyoma (UL) which seems to be likely e.g. for the group with MED12 mutations $(34-36,38)$, these considerations fit with a well-documented higher incidence of LMS in populations having a higher number of fibroids. A study by Laughlin et al. revealed that during pregnancy leiomyomas occurred 
more often in Black than in White women (18\% in Blacks, $8 \%$ in Whites, and $10 \%$ in Hispanics). In addition, the proportion of women with leiomyomas was found to increase much more steeply with age for Blacks than Whites (53). In another study on 18- to 30-year-old women, the prevalence of ultrasound-diagnosed fibroids was $15 \%$ overall, again with a clearly higher prevalence among Black women (26\% in Black women and 7\% in White women) (54). This has been reported by a number of other articles [see e.g. (55-57), reviewed by $(58,59)]$. An association between age at menarche and fibroid development apparently was observed in several studies both for Black and White women $(60,61)$.

Of note, a number of older studies also revealed a clearly higher incidence of uterine LMS in Black patients of AfroAmerican origin than in White Americans $(62,63)$. In order to determine the association of race with incidence, histology, treatment, and survival in women with uterine sarcoma, Brooks et al. analyzed the data of 2,677 patients from the Surveillance, Epidemiology, and End Results program. All patients had been diagnosed with a uterine sarcoma within a 10 -year period, including 300 who had leiomyosarcoma. Compared to White women, a significantly higher incidence of LMS was found in Black women $\left(1.5 / 10^{5}\right.$ for Blacks vs. $0.9 / 10^{5}$ for Whites, $\left.p<0.01\right)(64)$. More recently, in a series of 984 patients with uterine cancer from one institution (Montefiore Medical Center, NY, USA), Smotkin et al. found a significantly higher incidence of uterine leiomyosarcomas in Black than in White patients [5.2\% (16/308)] compared to $1.0 \%(4 / 382)$ of uterine cancer (65). Vice versa, in line with these considerations, power morcellation in case of patients of ethnicities showing a higher number of fibroids can be assumed to carry a higher risk of iatrogenic spreading of malignant and premalignant tumors. Accordingly, the risk of occult uterine cancer seems to be significantly associated with race/ethnicity (66).

In summary, in the case of multiple fibroids, preoperatively, patients should be aware of the higher risk associated with minimally invasive removal of these fibroids compared with hysterectomy.

\section{Follow-up of the Patients: Which Groups and Why?}

Without any doubt, women undergoing minimally invasive surgery requiring morcellation should know about the risk of spread of an occult malignancy by the procedure. Nevertheless, all studies addressing this point consider the risk of a malignant tumor already existing at the time of surgery. A more sophisticated question is if the risk of peritoneal implantation followed by secondary malignant transformation warrants additional attention. Besides malignant tumors, as in particular leiomyosarcomas, there are apparently other tumor entities prone to be spread by morcellation, i.e. particular subsets of STUMP, as well as atypical leiomyomas. There might be a high risk for some of these latter lesions giving rise to the so-called parasitic tumors characterized by their ability for peritoneal spread.

The recent WHO nomenclature refers to STUMP as to smooth-muscle tumors "with features that preclude an unequivocal diagnosis of leiomyosarcoma, but do not fulfil the criteria for a benign leiomyoma, or its variants, and raise concern that the neoplasm may behave in a malignant fashion" (67). Certainly, it is questionable whether these STUMPs constitute a separate clear-cut entity of tumors or rather represent different steps of a dynamic process of potentially malignant transformation. However, Croce et al. used comparative genomic hybridization to investigate a series of 29 patients with uterine STUMP with a follow-up period ranging between 12 and 156 months. By introducing a scoring system to evaluate genomic abnormalities, the tumors were split into two groups with different outcomes: A group comparable to leiomyomas and another similar to leiomyosarcomas, but more indolent (50). Heterogeneity and ongoing karyotypic evolution also detected by comparative genomic hybridization may be other genetic criteria assisting the differential diagnosis of STUMP versus leiomyosarcoma (51). The results of an attempt to differentiate between benign and malignant uterine smooth muscle tumors based on integrated comparative genomic and transcriptomic approach were published recently (68). Nevertheless, these methods all require available tumor tissue, whereas to the best of our knowledge, clear preoperative biomarker- or image-based assessment tools to recognize STUMP as well as atypical leiomyomas with sufficient specificity and sensitivity are lacking. Overall, the International Society for Gynecologic Endoscopy (ISGE) Task Force for Estimation of the Risk in Endoscopic Morcellation stated recently that in general, further studies and prospective data collection are greatly needed to improve sarcoma risk assessment (69).

In addition, unfortunately, most studies on the risk of spreading a malignancy do not address the problem of STUMP and neither do they give information on the prevalence of STUMP in their series nor address the problem of follow-up of these patients (70). Of note, once morcellated, peritoneal dissemination of STUMP does not seem to be an infrequent outcome. For example, dissemination without definite infiltration or invasion of adjacent tissue was noted in all four patients with STUMP undergoing follow-up exploratory laparotomy reported by Seidman et al. (71). Mowers et al. performed a retrospective chart review on six patients who underwent morcellation and were subsequently found to have a STUMP. Of these, five patients were found to have benign implants after surgical re-exploration (median time to re-exploration-7 weeks, range $=6-19.2$ weeks) (72). A trend towards an increased risk of recurrence was also noted by Raspagliesi et al. for patients undergoing morcellation of a STUMP (73) and Oduyebo et al. detected disseminated 
intraperitoneal disease in one out of four patients with presumed stage I STUMP even at immediate surgical reexploration (74). In line with these findings, Bogani et al. reported a case of a (morcellator) port-site implantation of a smooth muscle tumor seen 6 years after laparoscopic morcellation of a STUMP (75), thus also pointing to the significance of a relatively long follow-up period.

From the latter studies on the risk of power morcellation, sparse information is also available about the prevalence of so-called parasitic leiomyomas at the time of initial surgery. Parasitic leiomyomas lead to benign implants outside the uterus and are thought to be of iatrogenic origin in the majority of cases. Their presumable incidence among patients undergoing laparoscopic surgery including power morcellation is clearly higher than that of unexpected malignancies and is estimated to be in the range of 0.12 $0.95 \%$ (76). Unfortunately, little is known about their genetic background or their tendency to undergo malignant transformation. Nevertheless, their ability to implant ectopically is a reason for concern and there is insufficient data available to show whether the new environment or particular driver mutations may increase their ability to undergo malignant transformation. In general and as discussed in detail above, there is compelling evidence that, albeit as a very rare event, MED12-mutated fibroids seem to be able to undergo malignant transformation. Likewise, it is tempting to speculate that other much less frequent genetic subtypes of fibroids are also able to do so. This assumption is supported by recent findings obtained by our group. We presented the case of a 50-year-old woman who initially underwent laparoscopic subtotal hysterectomy because of symptomatic fibroids. While in none of the samples examined was histopathological evidence for malignancy noted, she presented again more than 2 years later with peritoneal nodules of a leiomyosarcoma. Akin to a fingerprint, these lesions revealed identical characteristic patterns of healed chromothripsis when compared with one of the initial tumors by genomic comparative hybridization (33). This case would have had escaped attention in any of the studies dealing only with the prevalence of primary LMS detected at the time of initial surgery. In general, there is currently no evidence whether or not ectopically placed fragments of parasitic UL have a higher risk of undergoing malignant transformation than the primary tumor.

Similarly, the so-called benign metastasizing leiomyomas (ICD-O 8898/1) require some attention. By definition, these are rare benign smooth muscle neoplasms originating in the uterus that have the potential to metastasize to distant sites, most commonly the lungs. Accordingly, they are often noted at distant sites several years after hysterectomy or myomectomy. Of note, the presence of UL-specific MED12 mutations has been described in apparent lung metastases in a patient suffering from benign metastasizing leiomyoma with fatal outcome (46), while other cases showed mutations different from those typically found in $\operatorname{UL}(77,78)$.

However, a considerably long follow-up period seems to be required for all cases instead of restricting follow-up evaluation to those patients not showing the classical histology of leiomyoma.

\section{Studies Involving Morcellated Specimens}

Morcellation usually results in a high number of tissue fragments and accordingly some problems arise when histopathological evaluation of the samples is performed (79). For example, if specimens are morcellated that contain more than one fibroid it is, as a rule, impossible to unambiguously allocate a single fragment to a particular tumor. Accordingly, it is also nearly impossible to ensure that every tumor has been examined histopathologically, which may result in tumors that have not been sampled at all. The presence of such non-sampled tumors can be expected to increase with an increasing number of morcellated fibroids, as well as with their decreasing size.

In their study on iatrogenic spreading of uterine mesenchymal neoplasms due to power morcellation, Seidman et al. have recommended histologicaI evaluation by generously sampling these cases with multiple lesions, "aiming to cut one section each per $1 \mathrm{~cm}$ of the dominant lesion(s), as well as several sections representing any secondary lesions", feeling that this may best recapitulate the degree of sampling performed on an equivalent en bloc resection. Moreover, it is recommended to sample "any areas of yellow coloration (as opposed to tan), any softened or 'degenerated' areas, tissue adjacent to necrosis, and any areas of hemorrhage" (71). Obviously, this procedure addresses the problem of undersampling and takes into account possible histological and heterogeneity along the lesions, but in general problems arising from the destruction of the spatial organization of the specimens are not avoided. Of note, Mittal and co-workers found leiomyoma-like areas in leiomyosarcomas in 18/26 tumors examined. In five of these cases, histology of the leiomyoma-like area corresponded to a usual-type leiomyoma and not to any of the variants (42). Nevertheless, to the best of our knowledge, commonly accepted rules for sampling considering the number and size of the single fibroids are lacking and it seems tempting to speculate that in rare cases, undersampling may preclude histological detection of malignant nodules. Therefore, the results of studies involving morcellated specimens are, as a rule, not well-suited to addressing risk estimates for unexpected malignancy.

\section{Conclusion}

It is well documented that morcellation of specimens obtained by laparoscopic hysterectomy or myomectomy is 

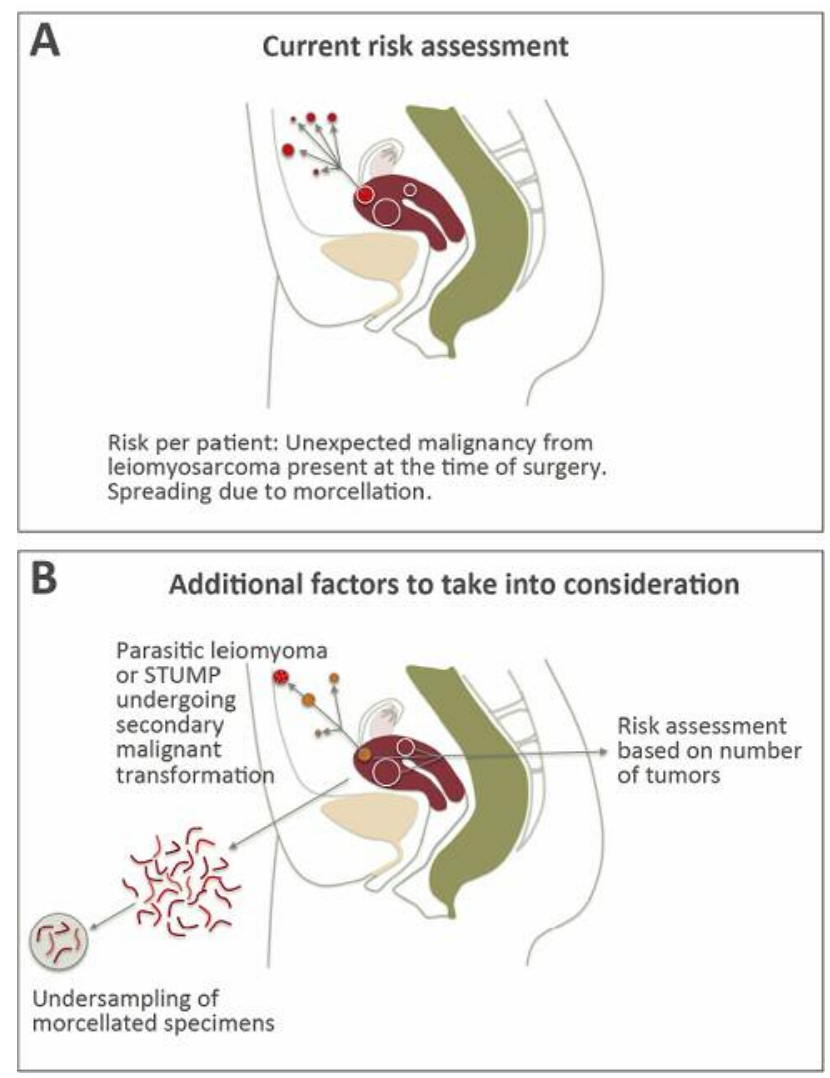

Figure 1. Classical assessment of risks associated with power morcellation of uterine fibroids compared to factors recommended for additional consideration. A: Evaluation of a patient's risk having an unexpected leiomyosarcoma at the time of surgery based on retrospective analyses of histopathology. B: Recommended factors to be taken into consideration for an advanced risk assessment. STUMP: Smooth muscle tumors of uncertain malignant potential.

associated with the risk of spreading an unexpected malignancy or of benign tissue [for review and clinical recommendations see (80)], but risk estimates vary over a broad range. However, a sufficient calculation of risks associated with the procedure is of outstanding importance when considering its pros and cons. We feel that previous risk estimates failed to address factors that can act as risk modifiers, as summarized in Figure 1. First of all, a major risk factor is the number of lesions that are morcellated which, according to the biology of the lesions, is assumed to act as a direct risk multiplier. Moreover, there is some evidence that in some cases, spreading of benign lesions such as the so-called parasitic leiomyomas may precede their malignant transformation at ectopic sites. Accordingly, for future studies, a clinical follow-up of all patients undergoing morcellation should be performed in order to avoid underestimating the risks associated with parasitic behavior of initially benign tumors of uterine smooth muscle. For assessment of the risk of spreading an unexpected malignancy, the results of available studies based on morcellated specimens should be interpreted with caution because of possible undersampling.

Finally, the Authors are well aware of the fact that they did not cite all relevant articles in this field. Accordingly, if such an article is missing from this review, it does not mean anything about its impact on the field.

\section{Conflicts of Interest}

J.B.: Invited speaker for Gedeon Richter.

\section{Authors' Contributions}

C. Holzmann: Conception, wrote the article, and approved the final version. W. Kuepker: Discussed and revised the article, approved the final version. B. Rommel: Discussed and revised the article, approved the final version. B. M. Helmke: Discussed and revised the article, approved the final version. J. Bullerdiek: Conception, wrote the article, approved the final version.

\section{Acknowledgements}

This work was supported by the Bremer Cancer Society, the regional member of the German Cancer Society.

\section{References}

1 Odejinmi F, Aref-Adib M, Liou N, Sideris M and Mallick R: Rethinking the issue of power morcellation of uterine fibroids: is morcellation the real problem or is this another symptom of disparity in healthcare provision? In Vivo 33: 1393-1401, 2019. PMID: 31471384 . DOI: 10.21873/invivo.11616

2 Siedhoff MT, Wheeler SB, Rutstein SE, Geller EJ, Doll KM, Wu JM and Clarke-Pearson DL: Laparoscopic hysterectomy with morcellation $v s$. abdominal hysterectomy for presumed fibroid tumors in premenopausal women: A decision analysis. Am J Obstet Gynecol 212: 591.e1-591.e8, 2015. PMID: 25817518. DOI: $10.1016 /$ j.ajog.2015.03.006

3 Canevari RA, Pontes A, Rosa FE, Rainho CA and Rogatto SR: Independent clonal origin of multiple uterine leiomyomas that was determined by $\mathrm{X}$ chromosome inactivation and microsatellite analysis. Am J Obstet Gynecol 193: 1395-1403, 2005. PMID: 16202732. DOI: 10.1016/j.ajog.2005.02.097

4 Mashal RD, Fejzo MLS, Friedman AJ, Mitchner N, Nowak RA, Rein MS, Morton CC and Sklar J: Analysis of androgen receptor DNA reveals the independent clonal origins of uterine leiomyomata and the secondary nature of cytogenetic aberrations in the development of leiomyomata. Genes Chromosomes Cancer 11: 1-6, 1994. PMID: 7529041. DOI: 10.1002/gcc.2870110102

5 Hashimoto K, Azuma C, Kamiura S, Kimura T, Nobunaga T, Kanai T, Sawada M, Noguchi S and Saji F: Clonal determination of uterine leiomyomas by analyzing differential inactivation of the X-chromosome-linked phosphoglycerokinase gene. Gynecol Obstet Invest 40: 204-208, 1995. PMID: 8529956. DOI: $10.1159 / 000292336$ 
6 Fujimoto J, Hirose R, Sakaguchi $\mathrm{H}$ and Tamaya T: Expression of size-polymorphic androgen receptor gene in uterine leiomyoma according to the number of cytosine, adenine, and guanine repeats in androgen receptor alleles. Tumor Biol 21: 3337, 2000. PMID: 10601839. DOI: 10.1159/000030108

7 Patton KT, Cheng L, Papavero V, Blum MG, Yeldandi A V, Adley BP, Luan C, Diaz LK, Hui P and Yang XJ: Benign metastasizing leiomyoma: Clonality, telomere length and clinicopathologic analysis. Mod Pathol 19: 130-140, 2006. PMID: 16357844. DOI: 10.1038/modpathol.3800504

8 Wu RC, Chao AS, Lee LY, Lin G, Chen SJ, Lu YJ, Huang HJ, Yen CF, Han CM, Lee YS, Wang TH and Chao A: Massively parallel sequencing and genome-wide copy number analysis revealed a clonal relationship in benign metastasizing leiomyoma. Oncotarget 8: 47547-47554, 2017. PMID: 28533481. DOI: 10.18632/oncotarget. 17708

9 Mäkinen N, Mehine M, Tolvanen J, Kaasinen E, Li Y, Lehtonen HJ, Gentile M, Yan J, Enge M, Taipale M, Aavikko M, Katainen R, Virolainen E, Böhling T, Koski TA, Launonen V, Sjöberg J, Taipale J, Vahteristo P and Aaltonen LA: MED12, the mediator complex subunit 12 gene, is mutated at high frequency in uterine leiomyomas. Science 334: 252-255, 2011. PMID: 21868628. DOI: $10.1126 /$ science. 1208930

10 Markowski DN, Bartnitzke S, Löning T, Drieschner N, Helmke BM and Bullerdiek J: MED12 mutations in uterine fibroids - their relationship to cytogenetic subgroups. Int $\mathbf{J}$ Cancer 131: 1528-1536, 2012. PMID: 22223266. DOI: $10.1002 / \mathrm{ijc} .27424$

11 Mäkinen N, Heinonen H-R, Moore S, Tomlinson IPM, van der Spuy ZM and Aaltonen LA: MED12 exon 2 mutations are common in uterine leiomyomas from South African patients. Oncotarget 2: 966-969, 2011. PMID: 22182697. DOI: 10.18632/ oncotarget. 370

12 Heinonen HR, Pasanen A, Heikinheimo O, Tanskanen T, Palin K, Tolvanen J, Vahteristo P, Sjöberg J, Pitkänen E, Bützow R, Mäkinen N and Aaltonen LA: Multiple clinical characteristics separate MED12-mutation-positive and -negative uterine leiomyomas. Sci Rep 7: 1015, 2017. PMID: 28432313. DOI: 10.1038/s41598-017-01199-0

13 Markowski DN, Helmke BM, Bartnitzke S, Ning TL and Bullerdiek J: Uterine fibroids: Do we deal with more than one disease? Int J Gynecol Pathol 33: 568-572, 2014. PMID: 25272295. DOI: $10.1097 /$ PGP.0000000000000096

14 Bertsch E, Qiang W, Zhang Q, Espona-Fiedler M, Druschitz S, Liu Y, Mittal K, Kong B, Kurita T and Wei J-J: MED12 and $H M G A 2$ mutations: Two independent genetic events in uterine leiomyoma and leiomyosarcoma. Mod Pathol 27: 1144-1153, 2014. PMID: 24390224. DOI: 10.1038/modpathol.2013.243

15 Mehine M, Kaasinen E, Mäkinen N, Katainen R, Kämpjärvi K, Pitkänen E, Heinonen H-R, Bützow R, Kilpivaara $\mathrm{O}$, Kuosmanen A, Ristolainen H, Gentile M, Sjöberg J, Vahteristo $\mathrm{P}$ and Aaltonen LA: Characterization of uterine leiomyomas by whole-genome sequencing. N Engl J Med 369: 43-53, 2013. PMID: 23738515. DOI: 10.1056/NEJMoa1302736

16 Bullerdiek $\mathrm{J}$ and Rommel B: Factors targeting MED12 to drive tumorigenesis? F1000Res 7: 359, 2018. PMID: 30647905. DOI: 10.12688/f1000research.14227.1

17 McGuire MM, Yatsenko A, Hoffner L, Jones M, Surti U and Rajkovic A: Whole exome sequencing in a random sample of North American women with leiomyomas identifies MED12 mutations in majority of uterine leiomyomas. PLoS One 7: e33251, 2012. PMID: 22428002. DOI: 10.1371/journal.pone.0033251

$18 \mathrm{Wu}$ X, Serna VA, Thomas J, Qiang W, Blumenfeld ML and Kurita T: Subtype-specific tumor-associated fibroblasts contribute to the pathogenesis of uterine leiomyoma. Cancer Res 77: 6891-6901, 2017. PMID: 29055020. DOI: 10.1158/00085472.CAN-17-1744

19 Jamaluddin MFB, Nahar P and Tanwar PS: Proteomic characterization of the extracellular matrix of human uterine fibroids. Endocrinology 159: 2656-2669, 2018. PMID: 29244110. DOI: 10.1210/en.2018-00151

20 Xie J, Ubango J, Ban Y, Chakravarti D, Kim JJ and Wei J-J: Comparative analysis of $\mathrm{AKT}$ and the related biomarkers in uterine leiomyomas with $M E D 12, H M G A 2$, and $F H$ mutations. Genes Chromosomes Cancer 57: 485-494, 2018. PMID: 29790226. DOI: $10.1002 /$ gcc. 22643

21 Heinonen HR, Mehine M, Mäkinen N, Pasanen A, Pitkänen E, Karhu A, Sarvilinna NS, Sjöberg J, Heikinheimo O, Bützow R, Aaltonen LA and Kaasinen E: Global metabolomic profiling of uterine leiomyomas. Br J Cancer 117: 1855-1864, 2017. PMID: 29073636. DOI: 10.1038/bjc.2017.361

22 Bloch J, Holzmann C, Koczan D, Helmke BM and Bullerdiek J: Factors affecting the loss of MED12-mutated leiomyoma cells during in vitro growth. Oncotarget 8: 34762-34772, 2017. PMID: 28410233. DOI: 10.18632/oncotarget.16711

23 Holzmann C, Markowski DN, Bartnitzke S, Koczan D, Helmke $\mathrm{BM}$ and Bullerdiek $\mathrm{J}$ : A rare coincidence of different types of driver mutations among uterine leiomyomas (UL). Mol Cytogenet 8: 76-82, 2015. PMID: 26468330. DOI: 10.1186/s13039-015-0177-9

24 Yoshida M, Sekine S, Ogawa R, Yoshida H, Maeshima A, Kanai Y, Kinoshita $\mathrm{T}$ and Ochiai A: Frequent MED12 mutations in phyllodes tumours of the breast. Br J Cancer 112: 1703-1708, 2015. PMID: 25839987. DOI: 10.1038/bjc.2015.116

25 Lim WK, Ong CK, Tan J, Thike AA, Ng CCY, Rajasegaran V, Myint SS, Nagarajan S, Nasir NDM, McPherson JR, Cutcutache I, Poore G, Tay ST, Ooi WS, Tan VKM, Hartman M, Ong KW, Tan BKT, Rozen SG, Tan PH, Tan P and Teh BT: Exome sequencing identifies highly recurrent $M E D 12$ somatic mutations in breast fibroadenoma. Nat Genet 46: 877-880, 2014. PMID: 25038752. DOI: $10.1038 / \mathrm{ng} .3037$

26 Staats B, Bonk U, Wanschura S, Hanisch P, Schoenmakers EF, Van de Ven WJ, Bartnitzke S and Bullerdiek J: A fibroadenoma with a $\mathrm{t}(4 ; 12)(\mathrm{q} 27 ; \mathrm{q} 15)$ affecting the HMGI-C gene, a member of the high mobility group protein gene family. Breast Cancer Res Treat 38: 299-303, 1996. PMID: 8739083. DOI: $10.1007 / \mathrm{bf01806149}$

27 Piscuoglio S, Murray M, Fusco N, Marchiò C, Loo FL, Martelotto LG, Schultheis AM, Akram M, Weigelt B, Brogi E and Reis-Filho JS: MED12 somatic mutations in fibroadenomas and phyllodes tumours of the breast. Histopathology 67: 719729, 2015. PMID: 25855048. DOI: 10.1111/his.12712

28 Nagasawa S, Maeda I, Fukuda T, Wu W, Hayami R, Kojima Y, Tsugawa K-I and Ohta T: MED12 exon 2 mutations in phyllodes tumors of the breast. Cancer Med 4: 1117-1121, 2015. PMID: 25865354. DOI: $10.1002 / \mathrm{cam} 4.462$

29 Pfarr N, Kriegsmann M, Sinn P, Klauschen F, Endris V, Herpel E, Muckenhuber A, Jesinghaus M, Klosterhalfen B, Penzel R, Lennerz JK, Weichert W and Stenzinger A: Distribution of MED12 mutations in fibroadenomas and phyllodes tumors of the 
breast-implications for tumor biology and pathological diagnosis. Genes Chromosomes Cancer 54: 444-452, 2015. PMID: 25931199. DOI: $10.1002 / \mathrm{gcc} .22256$

30 Holzmann C, Markowski DN, Koczan D, Helmke BM and Bullerdiek J: Genome-wide acquired uniparental disomy as well as chromosomal gains and losses in an uterine epithelioid leiomyoma. Mol Cytogenet 7: 19, 2014. PMID: 24593849. DOI: 10.1186/1755-8166-7-19

31 Holzmann C, Markowski DN, Koczan D, Küpker W, Helmke $\mathrm{BM}$ and Bullerdiek J: Cytogenetically normal uterine leiomyomas without MED12 mutations - a source to identify unknown mechanisms of the development of uterine smooth muscle tumors. Mol Cytogenet 7: 88, 2014. PMID: 25506394. DOI: $10.1186 / \mathrm{s} 13039-014-0088-1$

32 Holzmann C, Koczan D, Loening T, Rommel B and Bullerdiek J: Case Report: A low-grade uterine leiomyosarcoma showing multiple genetic aberrations including a bi-allelic loss of the retinoblastoma gene locus, as well as germ-line uniparental disomy for part of the long arm of chromosome 22. Anticancer Res 37: 2233-2237, 2017. PMID: 28476787. DOI: 10.21873/anticanres. 11559

33 Holzmann C, Saager C, Mechtersheimer G, Koczan D, Helmke BM and Bullerdiek J: Malignant transformation of uterine leiomyoma to myxoid leiomyosarcoma after morcellation associated with $A L K$ rearrangement and loss of 14q. Oncotarget 9: 27595-27604, 2018. PMID: 29963223. DOI: 10.18632/oncotarget.25137

34 Markowski DN, Huhle S, Nimzyk R, Stenman G, Löning T and Bullerdiek J: MED12 mutations occurring in benign and malignant mammalian smooth muscle tumors. Genes Chromosomes Cancer 52: 297-304, 2013. PMID: 23225304. DOI: $10.1002 /$ gcc. 22029

35 Ravegnini G, Mariño-Enriquez A, Slater J, Eilers G, Wang Y, Zhu M, Nucci MR, George S, Angelini S, Raut CP and Fletcher JA: MED12 mutations in leiomyosarcoma and extrauterine leiomyoma. Mod Pathol 26: 743-749, 2013. PMID: 23222489. DOI: $10.1038 /$ modpathol.2012.203

36 Pérot G, Croce S, Ribeiro A, Lagarde P, Velasco V, Neuville A, Coindre JM, Stoeckle E, Floquet A, MacGrogan G and Chibon $\mathrm{F}$ : MED12 alterations in both human benign and malignant uterine soft tissue tumors. PLoS One 7: e40015,2012. PMID: 22768200. DOI: 10.1371/journal.pone.0040015

37 Cuppens T, Moisse M, Depreeuw J, Annibali D, Colas E, GilMoreno A, Huvila J, Carpén O, Zikán M, Matias-Guiu X, Moerman P, Croce S, Lambrechts D and Amant F: Integrated genome analysis of uterine leiomyosarcoma to identify novel driver genes and targetable pathways. Int J Cancer 142: 12301243, 2018. PMID: 29063609. DOI: 10.1002/ijc.31129

38 Kämpjärvi K, Mäkinen N, Kilpivaara O, Arola J, Heinonen HR, Böhm J, Abdel-Wahab O, Lehtonen HJ, Pelttari LM, Mehine M, Schrewe H, Nevanlinna H, Levine RL, Hokland P, Böhling T, Mecklin J-P, Bützow R, Aaltonen LA and Vahteristo P: Somatic MED12 mutations in uterine leiomyosarcoma and colorectal cancer. Br J Cancer 107: 1761-1765, 2012. PMID: 23132392. DOI: $10.1038 /$ bjc.2012.428

39 Matsubara A, Sekine S, Yoshida M, Yoshida A, Taniguchi H, Kushima R, Tsuda H and Kanai Y: Prevalence of MED12 mutations in uterine and extrauterine smooth muscle tumours. Histopathology 62: 657-661, 2013. PMID: 23347103. DOI: 10.1111/his.12039

40 de Graaff MA, Cleton-Jansen A-M, Szuhai K and Bovée JVMG: Mediator complex subunit 12 exon 2 mutation analysis in different subtypes of smooth muscle tumors confirms genetic heterogeneity. Hum Pathol 44: 1597-604, 2013. PMID: 23517922. DOI: 10.1016/j.humpath.2013.01.006

41 Schwetye KE, Pfeifer JD and Duncavage EJ: MED12 exon 2 mutations in uterine and extrauterine smooth muscle tumors. Hum Pathol 45: 65-70, 2014. PMID: 24196187. DOI: 10.1016/j.humpath.2013.08.005

42 Mittal KR, Chen F, Wei JJ, Rijhvani K, Kurvathi R, Streck D, Dermody $\mathrm{J}$ and Toruner GA: Molecular and immunohistochemical evidence for the origin of uterine leiomyosarcomas from associated leiomyoma and symplastic leiomyoma-like areas. Mod Pathol 22: 1303-1311, 2009. PMID: 19633649. DOI: 10.1038/modpathol.2009.96

43 Mittal K and Joutovsky A: Areas with benign morphologic and immunohistochemical features are associated with some uterine leiomyosarcomas. Gynecol Oncol 104: 362-365, 2007. PMID: 17011615. DOI: 10.1016/j.ygyno.2006.08.034

44 Macciò A, Chiappe G, Kotsonis P, Lavra F, Serra M, Demontis $\mathrm{R}$ and Madeddu C: Abdominal leiomyosarcomatosis after surgery with external morcellation for occult smooth muscle tumors of uncertain malignant potential: A case report. Int J Surg Case Rep 38: 107-110, 2017. PMID: 28755615. DOI: 10.1016/j.ijscr.2017.07.020

45 Ahuja A, Agarwal P, Sardana R and Bhaskar S: Extensively metastasizing leiomyosarcoma: A diagnostic challenge. J Midlife Health 8: 148-150, 2017. PMID: 28983164. DOI: 10.4103/jmh. JMH_60_17

46 Ofori K, Fernandes H, Cummings M, Colby T and Saqi A: Benign metastasizing leiomyoma presenting with miliary pattern and fatal outcome: Case report with molecular analysis and review of the literature. Respir Med Case Rep 27: 100831, 2019. PMID: 30989050. DOI: 10.1016/j.rmcr.2019.100831

47 Emoto I, Moriuchi K, Kanbayashi S, Inohaya A, Ri Y and Sato Y: Power morcellation-induced dissemination of sarcomatous component arising in leiomyoma. J Obstet Gynaecol Res 44: 1843-1849, 2018. PMID: 29974551. DOI: 10.1111/jog.13694

48 Markowski DN, Holzmann C and Bullerdiek J: Genetic alterations in uterine fibroids- - a new direction for pharmacological intervention? Expert Opin Ther Targets 19: 1485-1494, 2015. PMID: 26293838. DOI: 10.1517/14728222.2015.1075510

49 Rommel B, Holzmann C and Bullerdiek J: Malignant mesenchymal tumors of the uterus - time to advocate a genetic classification. Expert Rev Anticancer Ther 16: 1155-1166, 2016. PMID: 27602604. DOI: 10.1080/14737140.2016.1233817

50 Croce S, Ribeiro A, Brulard C, Noel J-C, Amant F, Stoeckle E, Devouassoux-Shisheborah M, Floquet A, Arnould L, Guyon F, Mishellany F, Garbay D, Cuppens T, Zikan M, Leroux A, Frouin E, Duvillard P, Terrier P, Farre I, Valo I, Macgrogan GM and Chibon F: Uterine smooth muscle tumor analysis by comparative genomic hybridization: A useful diagnostic tool in challenging lesions. Mod Pathol 28: 1001-1010, 2015. PMID: 25932961. DOI: $10.1038 /$ modpathol.2015.3

51 Holzmann C, Markowski DN, von Leffern I, Löning T and Bullerdiek J: Patterns of chromosomal abnormalities that can improve diagnosis of uterine smooth muscle tumors. Anticancer Res 35: 6445-6456, 2015. PMID: 26637855.

52 Croce S, Ducoulombier A, Ribeiro A, Lesluyes T, Noel JC, Amant F, Guillou L, Stoeckle E, Devouassoux-Shisheboran M, Penel N, Floquet A, Arnould L, Guyon F, Mishellany F, Chakiba C, Cuppens T, Zikan M, Leroux A, Frouin E, Farre I, Genestie 
C, Valo I, Macgrogan G and Chibon F: Genome profiling is an efficient tool to avoid the STUMP classification of uterine smooth muscle lesions: A comprehensive array-genomic hybridization analysis of 77 tumors. Mod Pathol 31: 816-828, 2018. PMID: 29327710. DOI: 10.1038/modpathol.2017.185

53 Laughlin SK, Baird DD, Savitz DA, Herring AH, Hartmann KE, Laughlin SK, Baird DD, Savitz DA and Herring AH: Prevalence of uterine leiomyomas in the first trimester of pregnancy: An ultrasound-screening study. Obstet Gynecol 113: 630-635, 2009. PMID: 19300327. DOI: 10.1097/AOG.0b013e318197bbaf

54 Marsh EE, Ekpo GE, Cardozo ER, Brocks M, Dune T and Cohen LS: Racial differences in fibroid prevalence and ultrasound findings in asymptomatic young women (18-30 years old): A pilot study. Fertil Steril 99: 1951-1957, 2013. PMID: 23498888. DOI: $10.1016 /$ j.fertnstert.2013.02.017

55 Boclin K de LI, Faerstein E and Szklo M: Does life-course socioeconomic position influence racial inequalities in the occurrence of uterine leiomyoma? Evidence from the Pró-Saúde Study. Cad Saude Publica 30: 305-317, 2014. PMID: 24627059. DOI: $10.1590 / 0102-311$ X00025413

56 Stewart EA, Nicholson WK, Bradley L and Borah BJ: The burden of uterine fibroids for African-American women: Results of a national survey. J Womens Health 22: 807-816, 2013. PMID: 24033092. DOI: 10.1089/jwh.2013.4334

57 Faerstein E, Szklo M and Rosenshein N: Risk factors for uterine leiomyoma: A practice-based case-control study. I. AfricanAmerican heritage, reproductive history, body size, and smoking. Am J Epidemiol 153: 1-10, 2001. PMID: 11159139. DOI: 10.1093/aje/153.1.1

58 Eltoukhi HM, Modi MN, Weston M, Armstrong AY and Stewart EA: The health disparities of uterine fibroid tumors for African American women: A public health issue. Am J Obstet Gynecol 210: 194-199, 2014. PMID: 23942040. DOI: 10.1016/j.ajog. 2013.08.008

59 Catherino WH, Eltoukhi HM and Al-Hendy A: Racial and ethnic differences in the pathogenesis and clinical manifestations of uterine leiomyoma. Semin Reprod Med 31: 370-379, 2013. PMID: 23934698. DOI: $10.1055 / \mathrm{s}-0033-1348896$

60 Velez Edwards DR, Baird DD and Hartmann KE: Association of age at menarche with increasing number of fibroids in a cohort of women who underwent standardized ultrasound assessment. Am J Epidemiol 178: 426-433, 2013. PMID: 23817917. DOI: 10.1093/aje/kws585

61 Wise LA, Palmer JR, Harlow BL, Spiegelman D, Stewart EA, Adams-Campbell LL and Rosenberg L: Reproductive factors, hormonal contraception, and risk of uterine leiomyomata in African-American women: A prospective study. Am J Epidemiol 159: 113-123, 2004. PMID: 14718211. DOI: 10.1093/aje/kwh016

62 Harlow BL, Weiss NS and Lofton S: The epidemiology of sarcomas of the uterus. J Natl Cancer Inst 76: 399-402, 1986. PMID: 3456457.

63 Polednak AP: Incidence of soft $\square$ tissue cancers in Blacks and Whites in New York State. Int J Cancer 38: 21-26, 1986. PMID: 3721622. DOI: $10.1002 / \mathrm{ijc} .2910380105$

64 Brooks SE, Zhan M, Cote T and Baquet CR: Surveillance, Epidemiology, and End Results analysis of 2677 cases of uterine sarcoma 1989-1999. Gynecol Oncol 93: 204-208, 2004. PMID: 15047237. DOI: 10.1016/j.ygyno.2003.12.029

65 Smotkin D, Nevadunsky NS, Harris K, Einstein MH, Yu Y and Goldberg GL: Histopathologic differences account for racial disparity in uterine cancer survival. Gynecol Oncol 127: 616619, 2012. PMID: 22940487. DOI: 10.1016/j.ygyno.2012.08.025

66 Desai VB, Wright JD, Gross CP, Lin H, Boscoe FP, Hutchison $\mathrm{LM}$, Schwartz PE and $\mathrm{Xu} \mathrm{X}$ : Prevalence, characteristics, and risk factors of occult uterine cancer in presumed benign hysterectomy. Am J Obstet Gynecol 221: 39.e1-39.e14, 2019. PMID: 30853364. DOI: 10.1016/j.ajog.2019.02.051

67 Kurman RJ, Carcangiu ML, Herrington CS and Young RH (eds.): WHO Classification of Tumours of Female Reproductive Organs. Fourth Edition. Lyon, International Agency for Research on Cancer, 2014.

68 Mas A, Alonso R, Garrido-Gómez T, Escorcia P, Montero B, Jiménez-Almazán J, Martín J, Pellicer N, Monleón J and Simón C: The differential diagnoses of uterine leiomyomas and leiomyosarcomas using DNA and RNA sequencing. Am J Obstet Gynecol 221: 320.e1-320.e23, 2019. PMID: 31121144. DOI: 10.1016/j.ajog.2019.05.018

69 Sizzi O, Manganaro L, Rossetti A, Saldari M, Florio G, Loddo A, Zurawin R, van Herendael B and Djokovic D: Assessing the risk of laparoscopic morcellation of occult uterine sarcomas during hysterectomy and myomectomy: Literature review and the ISGE recommendations. Eur J Obstet Gynecol Reprod Biol 220: 30-38, 2018. PMID: 29149644. DOI: 10.1016/j.ejogrb. 2017.10.030

70 Bojahr B, De Wilde RL and Tchartchian G: Malignancy rate of 10,731 uteri morcellated during laparoscopic supracervical hysterectomy (LASH). Arch Gynecol Obstet 292: 665-672, 2015. PMID: 25820974. DOI: 10.1007/s00404-015-3696-z

71 Seidman MA, Oduyebo T, Muto MG, Crum CP, Nucci MR and Quade BJ: Peritoneal dissemination complicating morcellation of uterine mesenchymal neoplasms. PLoS One 7: e50058, 2012. PMID: 23189178. DOI: 10.1371/journal.pone.0050058

72 Mowers EL, Skinner B, McLean K and Reynolds RK: Effects of morcellation of uterine smooth muscle tumor of uncertain malignant potential and endometrial stromal sarcoma: Case series and recommendations for clinical practice. J Minim Invasive Gynecol 22: 601-606, 2015. PMID: 25596464. DOI: 10.1016/j.jmig.2015.01.007

73 Raspagliesi F, Maltese G, Bogani G, Fucà G, Lepori S, De Iaco P, Perrone M, Scambia G, Cormio G, Bogliolo S, Bergamini A, Bifulco G, Casali PG and Lorusso D: Morcellation worsens survival outcomes in patients with undiagnosed uterine leiomyosarcomas: A retrospective MITO group study. Gynecol Oncol 144: 90-95, 2017. PMID: 27817933. DOI: 10.1016/ j.ygyno.2016.11.002

74 Oduyebo T, Rauh-Hain AJ, Meserve EE, Seidman MA, Hinchcliff E, George S, Quade B, Nucci MR, Del Carmen MG and Muto MG: The value of re-exploration in patients with inadvertently morcellated uterine sarcoma. Gynecol Oncol 132: 360-365, 2014. PMID: 24296345. DOI: 10.1016/j.ygyno.2013.11.024

75 Bogani G, Ditto A, Martinelli F, Signorelli M, Chiappa V, Lorusso D, Sabatucci I, Carcangiu ML, Fiore M, Gronchi A and Raspagliesi F: Morcellator's port-site metastasis of a uterine smooth muscle tumor of uncertain malignant potential after minimally invasive myomectomy. J Minim Invasive Gynecol 23: 647-649, 2016. PMID: 26851127. DOI: 10.1016/j.jmig.2016.01.021

76 Van Der Meulen JF, Pijnenborg JMA, Boomsma CM, Verberg MFG, Geomini PMAJ and Bongers MY: Parasitic myoma after laparoscopic morcellation: A systematic review of the literature. 
BJOG An Int J Obstet Gynaecol 123: 69-75, 2016. PMID: 26234998. DOI: 10.1111/1471-0528.13541

77 Nguyen T-C, Drew PA, Dang LH and Yuan C: Cancer genes mutations in benign metastasizing leiomyoma: A case report. Cureus 11: e5154, 2019. PMID: 31523581. DOI: 10.7759/ cureus. 5154

78 Sõritsa D, Teder H, Roosipuu R, Tamm H, Laisk-Podar T, Soplepmann P, Altraja A, Salumets A and Peters M: Whole-exome sequencing of benign pulmonary metastasizing leiomyoma reveals mutation in the BMP8B gene. BMC Med Genet 19: 20, 2018 PMID: 29386003. DOI: 10.1186/s12881-018-0537-5

79 Pavlakis K, Messini I, Yiannou P, Gavresea T, Chrysanthakis D, Hilaris $\mathrm{G}$ and Panoskaltsis T: Morcellating uterine mesenchymal tumors: The pathologist's view. J Obstet Gynaecol Res 43: 580586, 2017. PMID: 28120430. DOI: 10.1111/jog.13240
80 Kho KA, Anderson TL and Nezhat $\mathrm{CH}$ : Intracorporeal electromechanical tissue morcellation: A critical review and recommendations for clinical practice. Obstet Gynecol 124: 787793, 2014. PMID: 25198260. DOI: 10.1097/AOG.00000 00000000448

Received November 4, 2019

Revised November 11, 2019

Accepted November 13, 2019 